\title{
Health-related quality of life before and during chemotherapy in patients with early-stage breast cancer
}

\author{
Monique Binotto ${ }^{1,2, a}$ iD, Tomás Reinertt ${ }^{2, b}$ iD, Gustavo Werutsky ${ }^{3, c}$ iD, Facundo Zaffaroni³ and Gilberto Schwartsmann ${ }^{1, d}$ iD \\ ${ }^{1}$ Postgraduate Program in Clinical Research, Hospital de Clínicas de Porto Alegre, HCPA, Porto Alegre, RS 90035-007, Brazil \\ ${ }^{2}$ Centro de Pesquisa da Serra Gaúcha, CEPESG, Caxias do Sul, RS 95020-450, Brazil \\ ${ }^{3}$ Latin American Cooperative Oncology Group, LACOG, Porto Alegre, RS 90619-900, Brazil \\ ahttps://orcid.org/0000-0002-5799-5390 \\ bhttps://orcid.org/0000-0003-4715-1415 \\ chttps://orcid.org/0000-0001-6271-105X \\ dhttps://orcid.org/0000-0002-7850-1644
}

\section{Abstract}

Objectives: Identify the main changes in the health-related quality of life (HRQoL) of women diagnosed with breast cancer (BC) undergoing chemotherapy.

Methods: Prospective cohort study that included 33 women diagnosed with clinical stages I-III BC and who underwent adjuvant chemotherapy. HRQoL was assessed using the EORTC QLQ-C30 and EORTC QLQ-BR23 instruments 1 week before the start of chemotherapy and during the third month of chemotherapy.

Results: There was a decline in the HRQoL scores of patients during treatment. Therefore, chemotherapy alters the patient's perceptions of their HRQoL since there is a decrease in global health status/quality of life (QoL) and functional scales such as physical functioning, role functioning, emotional functioning, social functioning, body image, sexual function and sexual enjoyment. We also observed an increase in side effects related to the systemic therapy, fatigue, nausea and vomiting, insomnia, appetite loss and diarrhoea, despite a decrease in breast symptoms and arm symptoms.

Conclusions: HRQoL was negatively affected during chemotherapy. Even though HRQoL assessment is a useful method for optimising patients' care, its implementation into clinical practice remains a challenge. Since side effects are very often underestimated, we consider that the evaluation of HRQoL parameters should be done for BC patients treated with chemotherapy.

Keywords: health-related quality of life, breast cancer, patient-reported outcomes, cancer

\section{Background}

According to current projections, the number of new cases of cancer is increasing and will grow from 14 million in 2012 to an annual global number of 22 million by 2030 [1]. Breast cancer $(\mathrm{BC})$ is the second most common cancer in the world in terms of new cases

Correspondence to: Monique Binotto Email: moniquebinotto@gmail.com

ecancer 2020, 14:1007

https://doi.org/10.3332/ecancer.2020.1007

Published: $27 / 01 / 2020$

Received: 24/10/2019

Publication costs for this article were supported by ecancer (UK Charity number 1176307).

Copyright: $@$ the authors; licensee ecancermedicalscience. This is an Open Access article distributed under the terms of the Creative Commons Attribution License (http:// creativecommons.org/licenses/by/3.0), which permits unrestricted use, distribution, and reproduction in any medium, provided the original work is properly cited. 
(1.7 million cases) and ranks fifth place as the cause of death [2]. Given the increasing survival rates after BC treatment, there is a greater emphasis on enhancing health-related quality of life (HRQoL) during and after oncologic therapies. Systemic therapies are associated with significant benefits in terms of reducing the risk of $B C$ recurrence [3] and are also associated with negative effects on HRQoL of survivors [4]. Additionally, given the fact that $\mathrm{BC}$ is being increasingly diagnosed in earlier stages as a consequence of screening programmes, the number of women receiving curative-intent adjuvant chemotherapy is also increasing.

It is necessary to consider the symptomatology and the adverse effects profile of different types of treatments that impact the patient's HRQoL. Chemotherapy, for example, causes significant side effects in women with BC such as fatigue, febrile neutropenia, depression, dyspnoea, pain, nausea and vomiting [5]. Besides, cancer-related sequelae can include emotional distress like uncertainty or fear of recurrence and posttraumatic stress symptoms, pain and limitations in the ability to work [6]. Although there is a consensus in the literature that chemotherapy is the treatment that most impacts the HRQoL, specific real-world data (RWD) about the impact of adjuvant chemotherapy in $\mathrm{HRQ}$ oL of $\mathrm{BC}$ patients are not clear.

The concept of quality of life (QoL) can be defined as the individual's perception of his position in life in the context of culture and value systems in which they live and in relation to their goals, expectations, standards and concerns [7]. When this concept is restricted to health perceptions, the term is called HRQoL. This term is a multi-domain concept, which represents the general perception of the patient focusing on the effect of disease and treatment on other aspects of life [8]. Therefore, the term HRQoL is used to include in this assessment those aspects that are generally not included in the health context (such as income, freedom and quality of the environment). Therefore, focusing on the assessment of HRQoL means to evaluate almost all aspects of life that are health-related [9].

Therefore, it is essential to understand the patients' needs in order to improve HRQoL and to stabilise mental, social and physical health, in addition to the management of specific signs and symptoms throughout the treatment. In this context, the purpose of this study was to evaluate the HRQoL in $B C$ patients and to compare the patterns before and during chemotherapy.

\section{Methods}

We conducted a prospective cohort study to evaluate HRQoL in 33 Brazilian BC patients who performed the first oncological consultation at a private oncology clinic in the city of Caxias do Sul, RS, Brazil. The inclusion criteria were women $\geq 18$ years of age, histologically confirmed invasive stages I-III BC who were treated with breast surgery and received adjuvant or neoadjuvant treatment with an anthracycline and/or taxane-based chemotherapy.

The evaluation of patients HRQoL used the EORTC QLQ-C30 (European Organisation for Research and Treatment of Cancer Quality of Life Core Questionnaire) and EORTC QLQ-BR23 (EORTC BC-specific Quality of Life Questionnaire) [10]. All of these instruments are validated, translated to Portuguese, standardised and self-administrative [11]. Patients completed the questionnaires in two periods, i.e. 1 week before the beginning of the chemotherapy treatment (baseline) and in the third month of treatment, approximately in the fourth chemotherapeutic cycle (3-month follow-up). The following information were collected from medical records such as sociodemographic data (educational level and marital status), habits (smoking and alcoholism), menopausal status, family history of cancers and performance status - evaluated no more than 2 weeks before enrolment into the study using the Eastern Cooperative Oncology Group Scale [12].

We evaluated the questionnaire according to standardised methodology recommended by the EORTC Group. Data analysis was performed using SAS version 9.4. The sociodemographic and clinical-epidemiological results were described by means, standard deviation, median, minimum, maximum, first quartile $\left(1^{\circ} \mathrm{Q}\right)$ and third quartile $\left(3^{\circ} \mathrm{Q}\right)$ or using of absolute and relative frequencies. To analyse the paired data in the two follow-up times, the Wilcoxon test was used, considering statistically significant those results whose $p$-value $(p)$ was $\leq 0.05$. There were no adjustments for multiplicity.

This study was approved by the Research Ethics Committee (numbered 2.106.211, CAAE: 66288117.0.0000.5327). All the participants signed the Term of Free and Informed Consent, agreeing to participate in this research. 


\section{Results}

\section{Study population}

Results concerning sociodemographic and clinical characteristics from the 33 patients included in the study are described in Tables 1 and 2. The patients had a median age of 51.4 years and were mostly married (75.8\%), almost half of them studied until elementary or middle school (48.5\%), the majority were non-smokers (72.7\%) and non-alcoholic (81.8\%). Regarding patients' clinical characteristics, almost half of them were premenopausal in diagnosis (42.4\%), and most of them had a family history of cancer (60.6\%).

\section{HRQoL scores}

With the use of EORTC QLQ-C30 questionnaire, a significant difference was observed between the evaluation performed before the start of the chemotherapy and the reassessment in the third month treatment (Table 3 and Figure 1). The scores decreased significantly in the global health status/QoL $(p<0.0001)$ and in the functional scales such as physical functioning $(p<0.0001)$, role functioning $(p$ $<0.0001)$, emotional functioning ( $p<0.0001)$ and social functioning $(p<0.0001)$. In terms of symptoms, there was a significant increase in the scales of fatigue $(p<0.0001)$, nausea and vomiting $(p=0.0002)$, insomnia $(p=0.0017)$, appetite loss $(p=0.0098)$ and diarrhoea $(p=0.0241)$.

Significant alterations were also observed in the EORTC QLQ-BR23 questionnaire before and during chemotherapy (Table 4). Functional scales obtained lower scores in the second evaluation, performed during treatment, for the body image ( $p=0.0005)$, sexual function $(p<0.0001)$ and sexual enjoyment $(p=0.0002)$. Symptom scales increased in systemic therapy side effects $(p<0.0001)$ and decreased of breast symptoms $(p=0.0040)$ and arm symptoms $(p=0.0253)$.

Table 1. Patients' characteristics.

\begin{tabular}{|l|c|}
\hline \multicolumn{1}{|c|}{ Characteristics } & $n$ (\%) \\
\hline Age, mean (SD) & $51.4(11.8)$ \\
\hline Marital status \\
\hline Married & $25(75.8)$ \\
Single & $8(24.2)$ \\
\hline Educational level & $16(48.5)$ \\
\hline Elementary or middle school & $12(36.4)$ \\
High school & $5(15.1)$ \\
College & \\
\hline Habits (smoke) & $24(72.7)$ \\
\hline Non-smoker & $4(12.1)$ \\
Former smoker & $5(15.2)$ \\
Current smoker & $27(81.8)$ \\
\hline Habits (alcoholism) & $6(18.2)$ \\
\hline Non-alcoholic
\end{tabular}


Table 2. Patients' characteristics.

\begin{tabular}{|l|c|}
\hline \multicolumn{1}{|c|}{ Characteristics } & $\mathbf{n}(\%)$ \\
\hline Menopausal state & \\
\hline Premenopausal & $14(42.4)$ \\
Perimenopausal & $7(21.2)$ \\
Postmenopausal & $12(36.4)$ \\
\hline Family history of cancer & $13(39.4)$ \\
\hline No & $4(12.1)$ \\
Yes (breast) & $7(21.2)$ \\
Yes (breast and other) & $9(27.3)$ \\
Yes (other) & \\
\hline ECOG performance status & $18(54.5)$ \\
\hline 0 & $15(45.5)$ \\
1 & \\
\hline Mode of BC detection & $13(39.4)$ \\
\hline Screen detected & $19(57.6)$ \\
Symptomatic & $1(3.0)$ \\
Unknown
\end{tabular}

\section{Discussion}

The evaluation of HRQoL can be very useful to measure the impact of treatment on health-disease perceptions, psychological issues, life satisfaction and patients' well-being [13]. BC patients are at increased risk of treatment side effects on general HRQoL, e.g., physical conditions (fatigue, sleep disorders and pain) and psychological disorders (depression, anxiety, fear of recurrence, problems related to sexuality and body image) $[6,14]$. Also, chemotherapy alters the patient's perceptions of their HRQoL since there is an increase in symptoms and a decrease in functional scales [15-17].

This study is important because we performed an analysis with RWD from Brazilian BC patients. In addition, HRQoL analysed are rare outside of randomised clinical trials. Thus, patients analysed in this study may describe more realistically the changes in HRQoL triggered during chemotherapy. These data may help clinical oncologists to measure the magnitude of the effect that chemotherapy may have on potential biopsychosocial characteristics, in addition to the classic symptoms that chemotherapy triggers in patients.

In this study, the HRQoL of BC patients undergoing neoadjuvant and adjuvant chemotherapy is worse when comparing the period before the start of treatment with the one during chemotherapy. Global health status/QoL declined due to chemotherapy indicating that women with BC consider that their health status is deteriorated during treatment. Similarly, Leinert et al [15] showed that global health deteriorated during chemotherapy treatment also in the context of an increase in symptoms attributed to systemic treatment.

Additionally, BC patients have a high risk of developing alterations in their psychological functions, which also has a negative impact on HRQoL [18]. According to the literature $[19,20]$, there is a considerable decline in the scales of emotional functioning and body image during chemotherapy. It is believed that altered body image is a critical psychosocial issue for women with BC [21]. This can be explained because body image may be impacted by the patients' perceptions about what others think, thereby affecting person's sense of self-esteem. The global HRQoL, the low social and emotional functioning of BC patients were significantly associated with psychological variables [22]. Thus, it is understood that, in general, the severity of the symptoms is associated with adverse psycho-behavioural characteristics [23].

Among the women who received chemotherapy, a decrease was observed over time in breast and arm, which can be associated with the improvement and resolution of post-operative complications such as pain, function limitation of the upper limb and lymphedema. A simi- 
lar result was found in the study by Winters et al [24], whose patients also reported improvements in locoregional symptoms over time. Moreover, there were no differences between the periods in cognitive functioning, pain, dyspnoea, constipation, financial difficulties and future perspective between the two evaluations.

Table 3. Comparison of HRQoL between the study segments (EORTC QLQ-C30).

\begin{tabular}{|c|c|c|c|c|c|c|c|c|}
\hline & & \multirow{2}{*}{$\mathrm{N}$} & \multirow{2}{*}{ Mean } & \multirow{2}{*}{$\begin{array}{l}\text { Standard } \\
\text { deviation }\end{array}$} & \multirow{2}{*}{ Median } & \multicolumn{2}{|c|}{ Quartiles } & \multirow{2}{*}{$p$-value } \\
\hline & & & & & & $1^{\circ}$ & $3^{\circ}$ & \\
\hline \multicolumn{9}{|l|}{ Global health status/QoL } \\
\hline \multirow{2}{*}{ Global health status/QoL } & Baseline & 33 & 77.77 & 16.23 & 83.30 & 66.70 & 83.30 & \multirow{2}{*}{$<0.0001^{*}$} \\
\hline & Three-month follow-up & 33 & 55.82 & 16.067 & 58.33 & 41.70 & 66.70 & \\
\hline \multicolumn{9}{|l|}{ Functional scales } \\
\hline \multirow[t]{2}{*}{ Physical functioning } & Baseline & 33 & 89.73 & 11.58 & 93.00 & 87.00 & 100.00 & \multirow{2}{*}{$<0.0001^{*}$} \\
\hline & Three-month follow-up & 33 & 69.09 & 15.44 & 73.33 & 60.00 & 80.00 & \\
\hline \multirow[t]{2}{*}{ Role functioning } & Baseline & 33 & 80.82 & 19.10 & 83.00 & 67.00 & 100.00 & \multirow{2}{*}{$<0.0001^{*}$} \\
\hline & Three-month follow-up & 33 & 52.53 & 23.24 & 50.00 & 50.00 & 66.67 & \\
\hline \multirow[t]{2}{*}{ Emotional functioning } & Baseline & 33 & 70.21 & 19.42 & 75.00 & 58.00 & 83.00 & \multirow{2}{*}{$<0.0001^{*}$} \\
\hline & Three-month follow-up & 33 & 46.21 & 20.95 & 50.00 & 41.67 & 58.33 & \\
\hline \multirow[t]{2}{*}{ Cognitive functioning } & Baseline & 33 & 81.82 & 20.56 & 83.30 & 66.70 & 100.00 & \multirow{2}{*}{0.3050} \\
\hline & Three-month follow-up & 33 & 75.25 & 25.38 & 83.33 & 66.70 & 100.00 & \\
\hline \multirow[t]{2}{*}{ Social functioning } & Baseline & 33 & 87.38 & 18.64 & 100.00 & 66.70 & 100.00 & \multirow{2}{*}{$<0.0001^{*}$} \\
\hline & Three-month follow-up & 33 & 59.60 & 22.44 & 66.70 & 50.00 & 83.30 & \\
\hline \multicolumn{9}{|l|}{ Symptom scales } \\
\hline \multirow[t]{2}{*}{ Fatigue } & Baseline & 33 & 14.14 & 16.50 & 11.11 & 0.00 & 22.22 & \multirow{2}{*}{$<0.0001^{*}$} \\
\hline & Three-month follow-up & 33 & 55.56 & 19.84 & 55.56 & 44.44 & 66.67 & \\
\hline \multirow[t]{2}{*}{ Nausea and vomiting } & Baseline & 33 & 1.01 & 4.04 & 0.00 & 0.00 & 0.00 & \multirow{2}{*}{$0.0002^{*}$} \\
\hline & Three-month follow-up & 33 & 13.64 & 21.02 & 0.00 & 0.00 & 16.67 & \\
\hline \multirow[t]{2}{*}{ Pain } & Baseline & 33 & 27.78 & 27.85 & 16.67 & 0.00 & 50.00 & \multirow{2}{*}{0.3835} \\
\hline & Three-month follow-up & 33 & 32.32 & 26.98 & 33.33 & 16.67 & 50.00 & \\
\hline Dyspnoea & Baseline & 33 & 7.07 & 18.18 & 0.00 & 0.00 & 0.00 & \\
\hline & Three-month follow-up & 33 & 14.14 & 26.39 & 0.00 & 0.00 & 33.33 & 0.2529 \\
\hline Insomnia & Baseline & 33 & 28.28 & 32.41 & 33.33 & 0.00 & 33.33 & $0.0017 *$ \\
\hline & Three-month follow-up & 33 & 52.53 & 31.21 & 33.33 & 33.33 & 66.67 & $0.001 /$ \\
\hline Appetite loss & Baseline & 33 & 7.07 & 18.18 & 0.00 & 0.00 & 0.00 & ०००98* \\
\hline & Three-month follow-up & 33 & 22.22 & 29.66 & 0.00 & 0.00 & 33.33 & 0.0070 \\
\hline Constipation & Baseline & 33 & 18.18 & 28.98 & 0.00 & 0.00 & 33.33 & 0.0930 \\
\hline & Three-month follow-up & 33 & 31.31 & 35.30 & 33.33 & 0.00 & 66.67 & 0.0730 \\
\hline Diarrhoea & Baseline & 33 & 1.01 & 5.80 & 0.00 & 0.00 & 0.00 & $0.0241^{*}$ \\
\hline & Three-month follow-up & 33 & 9.09 & 17.23 & 0.00 & 0.00 & 16.67 & $0.0<41$ \\
\hline Financial difficulties & Baseline & 33 & 26.26 & 28.57 & 33.33 & 0.00 & 33.33 & \\
\hline & Three-month follow-up & 33 & 30.30 & 29.30 & 33.33 & 0.00 & 33.33 & 0.5582 \\
\hline
\end{tabular}

* Statistically significant $p$-value from the Wilcoxon test 
Table 4. Comparison of HRQoL between study segments. Specific questionnaire for BC (EORTC QLQ-BR23).

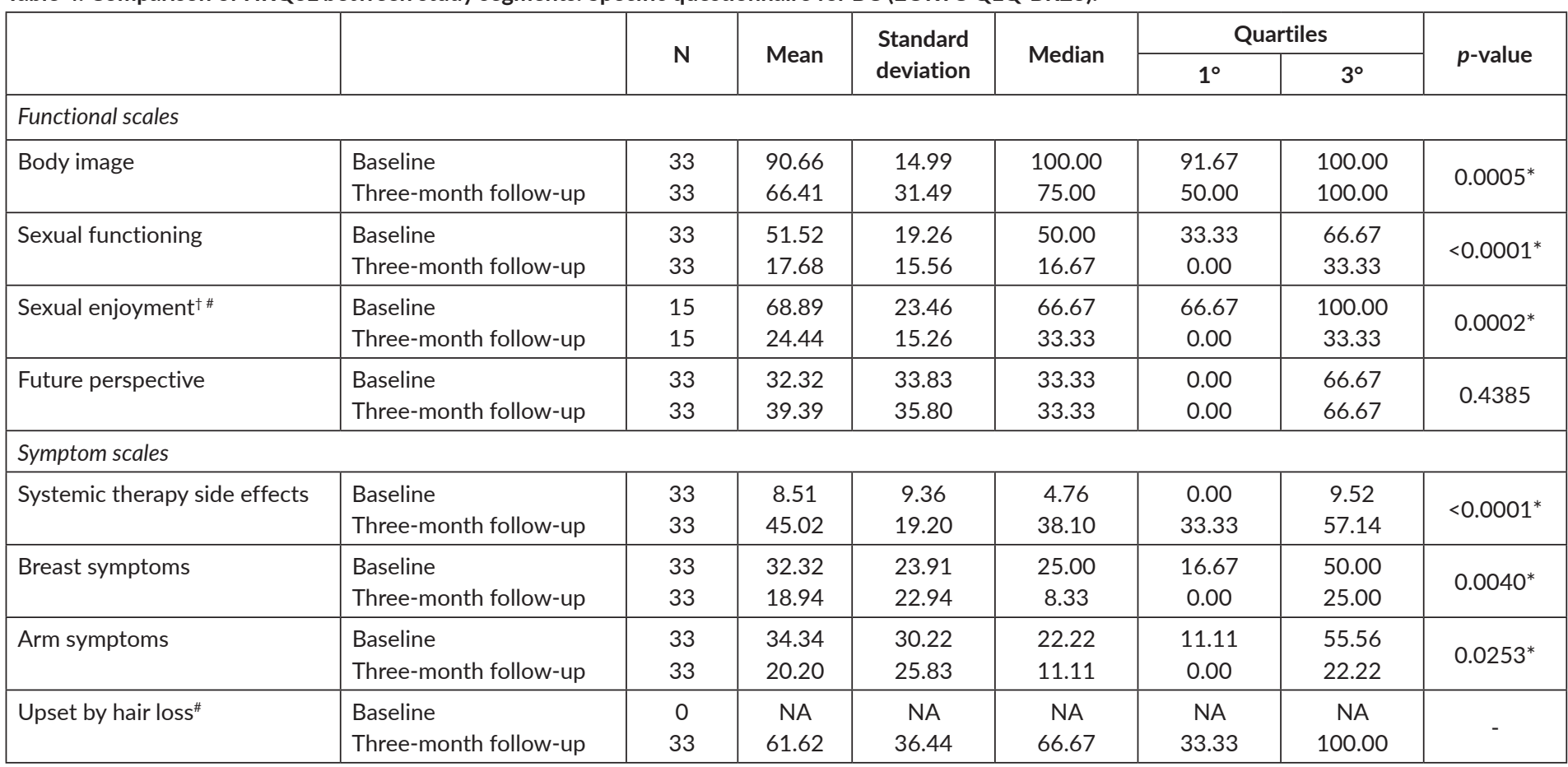

*Statistically significant $p$-value from the Wilcoxon test

†Only 15 women with valid baseline and follow-up information (third month) were considered. NA, not applicable; there was no valid information available.

\#According to the EORTC Scoring Manual [25], the variation in the number of responses in EORTC QLQ-BR23 is predicted since the fields 'sexual

enjoyment' and 'upset by hair loss' do not apply when the responses related to these scales are 'no'.

These scales are about physical effort, sleep and help with basic needs and the ability to work or perform daily activities. This consequence is common in patients with $\mathrm{BC}$ due to disease- and treatment-related limitations in their functional status. Similar results are described in the literature $[15,16]$ since physical functioning is consistently better in the baseline compared to the end of treatment due to the development of fatigue [16]. Regarding the upset by hair loss scale, it is not possible to compare the segments. According to the EORTC Scoring Manual [25], the variation in the number of responses in EORTC QLQ-BR23 is predicted since scales upset by hair loss and sexual enjoyment are not applicable when the responses related to this scale are 'no'. Even so, a high score on this scale represents that the symptom negatively impacted the patient's HRQoL [25]. Therefore, alopecia is life altering and the patients considered these side effects distressing [21]. In this way, this alteration can develop a fear regarding the way it will be seen or judged by the others, causing the withdrawal from social life because it feels uncomfortable in public places $[21,26]$.

Several factors are associated with the social withdrawal of patients with BC. There is social stigmatisation about the disease, which can affect the relationship of the BC woman with other people. In our study, social functioning was impaired throughout chemotherapy, which means that physical condition and treatment interfered in the way a patient relates to his family and participates in social activity. Similar results were reported in other studies [16, 27], demonstrating the impact that chemotherapy treatment can have on social relations. On the other hand, larger social networks are related to higher HRQoL after a diagnosis of BC, when the patient has greater social support from family and friends [28]. It is understood that sexuality, after a cancer diagnosis, can be influenced by changes in hormone levels and changes in body image perception [29]. Our findings are in agreement with the study of Hall et al [30], which indicated that most of the systemic effects of chemotherapy tend to compromise women's sexuality in the short- and long-term. The findings of increased systemic adverse effects (systemic therapy side effects, fatigue, nausea and vomiting, insomnia, appetite loss and diarrhoea) in patients treated with chemotherapy agreed with the broader toxicity results expected for the treatment. 

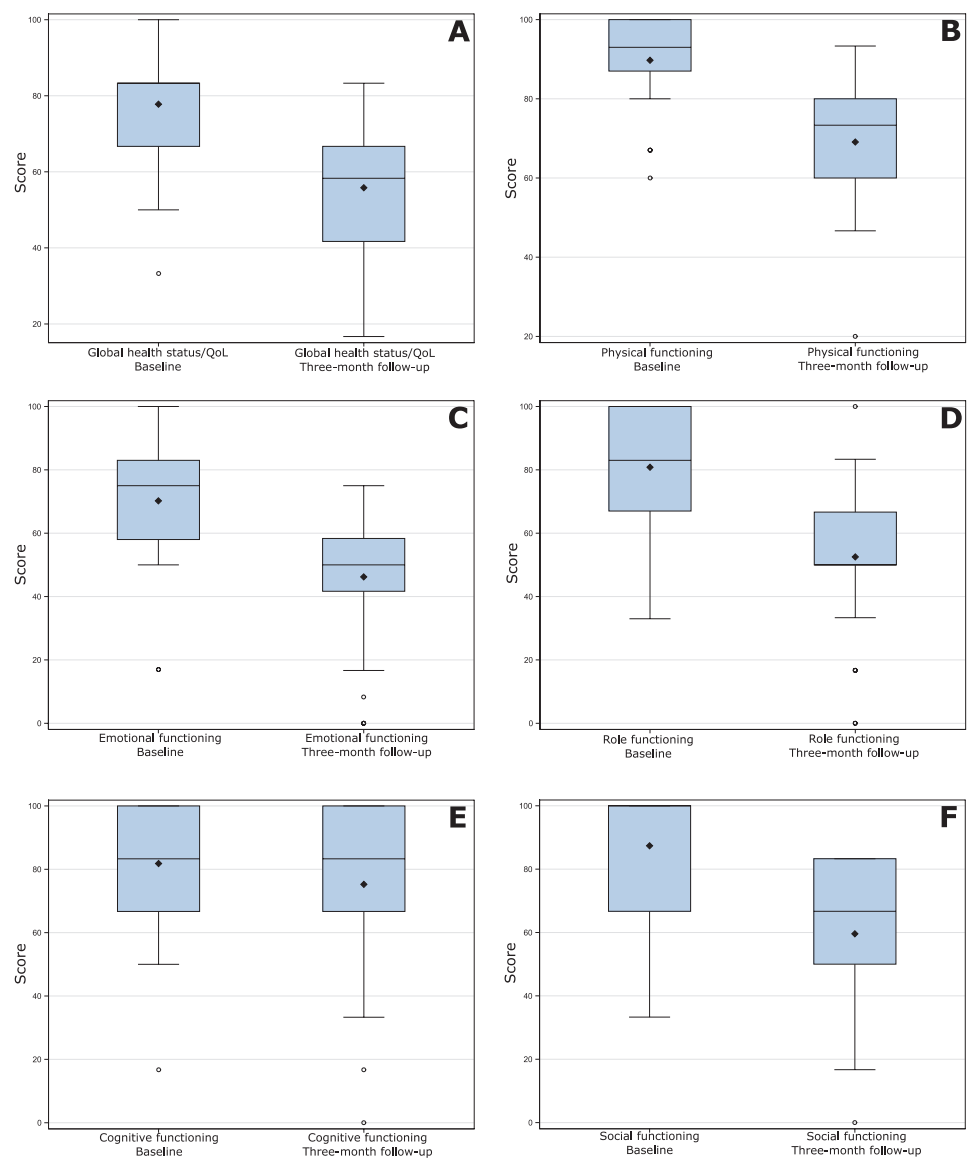

A: Global health status/QoL; B: Physical functioning; C: Emotional functioning; D: Role functioning; E: Cognitive functioning; F: Social functioning

Figure 1. Comparison of HRQoL between study segments in global health status/QoL and functional scales (EORTC QLQ-C30).

Chemotherapy may also be responsible for exacerbating low-grade toxicities [31] such as diarrhoea, which may be sufficient to impair patients' HRQoL. Besides, insomnia is also a common problem in cancer patients. The concomitant effect of chemotherapy on insomnia symptoms is mediated by a range of symptoms of oncologic therapy such as urinary symptoms, nausea, night sweats and digestive symptoms [32]. Changes in taste and smell often occur as a side effect of chemotherapy. These changes affect food behaviour, reducing overall food intake or restricting the intake of specific foods [33].

The current study has as a limitation due to the absence of more evaluations after the one realised at the 3 months of chemotherapy treatment. Thus, it was not possible to evaluate if the impact of chemotherapy on the HRQoL of these patients was reversible to the basal levels after a longer period. Despite this limitation, the objective of the study was reached the evaluation of the impact of chemotherapy on the patient's HRQoL and the identification of possible factors that have an impact on the social and psychological parameters of the patient's well-being. More studies should be done in a similar population in order to analyse the long-term HRQoL effects of adjuvant chemotherapy in $\mathrm{BC}$ patients. One additional limitation is that only patients treated in the private setting were included, and therefore, our study population may not represent adequately the patients treated in the public health system.

Additionally, it is important to emphasise that there is a variety of chemotherapeutic agents and combinations used for the treatment of BC and each regimen is associated with a specific adverse effect profile. All of our patients received standard anthracycline and taxane-based che- 
motherapy regimens. Therefore, our findings cannot be extrapolated to patients treated with different schemas such as Cyclophosphamide, Methotrexate, and 5-Fluorouracil (CMF) and capecitabine that usually have a milder side effects profile and probably impact HRQoL in a different way.

The findings of our study contribute to the knowledge about the needs of women with BC during chemotherapy treatment. The results show that the HRQoL of these patients is negatively altered during chemotherapy, and therefore, there is a need for interventions in oncology and research in this area. The implementation of HRQoL assessment in clinical practice has already been tested in a randomised controlled trial [34]. In this study, the routine assessment of cancer patients' HRQoL indicated that is an effective approach for improves the quality of healthcare (with a positive impact on physician-patient communication). Despite the difficulties in implementing an HRQoL assessment programme in practice in Latin American countries, like Brazil, this parameter must be considered to provide chemotherapy every time for early BC given that short- and long-term impacts on QoL are often under estimated.

The period just after diagnosis and treatment is a critical point to the assessment of patient's needs for coping and planning. Because of this, healthcare providers should give special attention to potential issues in the adjustment of the patient to the treatment. The quality of the information provided at this moment may improve patients' sense of well-being [21]. Physicians and health's professionals should screen patients often for systemic therapy side effects and use symptom scales. Screening can consider also the patient's perceptions of global health status and QoL, physical functioning, role functioning, emotional functioning and social functioning. In this setting, basic communication skills and empathy are essential when conducting a psychosocial assessment.

It is important to understand patient and family goals in order to help the adjustment of the treatment around their priorities and ensure that we care for the whole person, considering perceptions about cancer care and well-being during treatment. Minimising treatment adverse effects and managing strategies to help the patient overcome this step are critical to the improvement of HRQoL. Using this information, we can tailor our treatment strategy to the needs of each patient.

\section{Conclusions}

The HRQoL of BC patients is generally worse during the third month of chemotherapy when compared to the period before the start of treatment. Our findings are in agreement with what has been reported in the literature. Although the implementation of QoL assessment methodologies in the care routine is still a challenge, patients could have many benefits associated with the improvement of HRQoL and wellbeing during the treatment. Researchers and healthcare providers should continue to extend models for disseminating knowledge about HRQoL. Moreover, the analysis of HRQoL in the real-world setting is important and should be considered a priority in future research within this field.

\section{Conflicts of interest}

The authors have no conflicts of interest to declare.

\section{Funding statement}

The authors received no financial support for the research, authorship and/or publication of this article.

\section{Authors' contributions}

All the authors contributed to the elaboration of this paper and agreed with the content. 


\section{Trial registration}

Not applicable.

\section{References}

1. Jemal A, Vineis P, and Bray F, et al (2014) The Cancer Atlas 2nd edn (Atlanta: American Cancer Society) [www.cancer.org/canceratlas]

2. Ferlay J, Soerjomataram I, and Dikshit R, et al (2015) Cancer incidence and mortality worldwide: sources, methods and major patterns in GLOBOCAN 2012 Int J Cancer 136 E359-E386 https://doi.org/10.1002/ijc.29210

3. Anampa J, Makower D, and Sparano JA (2015) Progress in adjuvant chemotherapy for breast cancer: an overview BMC Med 13195 https://doi.org/10.1186/s12916-015-0439-8 PMID: 26278220 PMCID: 4538915

4. Chopra I and Kamal KM (2012) A systematic review of quality of life instruments in long-term breast cancer survivors Health Qual Life Outcomes 1014 https://doi.org/10.1186/1477-7525-10-14 PMID: 22289425 PMCID: 3280928

5. Ferreira RG and Franco LF de R (2017) Efeitos colaterais decorrentes do tratamento quimioterápico no câncer de mama: revisão bibliográfica Rev da Univ Val do Rio Verde https://doi.org/10.5892/ruvrd.v15i2.3759

6. Stanton AL, Rowland JH, and Ganz PA (2015) Life after diagnosis and treatment of cancer in adulthood: contributions from psychosocial oncology research Am Psychol 70 159-174 https://doi.org/10.1037/a0037875 PMID: 25730722

7. WHOQOL Group (1994) Development of the WHOQOL: rationale and current status Int J Ment Health 23 24-56 https://doi.org/10.1 080/00207411.1994.11449286

8. Food and Drug Administration (2006) Guidance for industry: patient-reported outcome measures: use in medical product development to support labeling claims: draft guidance Health Qual Life Outcomes 479 https://doi.org/10.1186/1477-7525-4-79 PMID: 17034633 PMCID: 1629006

9. Guyatt GH, Feeny DH, and Patrick DL (1993) Measuring health-related quality of life Ann Intern Med 118 622-629 https://doi. org/10.7326/0003-4819-118-8-199304150-00009 PMID: 8452328

10. Aaronson NK, Ahmedzai S, and Bergman B, et al (1993) The European Organization for Research and Treatment of Cancer QLQ-C30: a quality-of-life instrument for use in international clinical trials in oncology J Natl Cancer Inst 85 365-376 https://doi.org/10.1093/ jnci/85.5.365 PMID: 8433390

11. Michels FAS, Latorre M do RD de O, and Maciel M do S (2013) Validity, reliability and understanding of the EORTC-C30 and EORTCBR23, quality of life questionnaires specific for breast cancer Rev Bras Epidemiol 16 352-363 https://doi.org/10.1590/S1415790X2013000200011 PMID: 24142007

12. Oken MM, Creech RH, and Tormey DC, et al (1982) Toxicity and response criteria of the Eastern Cooperative Oncology Group Am J Clin Oncol 5 649-655 https://doi.org/10.1097/00000421-198212000-00014 PMID: 7165009

13. Montazeri A (2008) Health-related quality of life in breast cancer patients: a bibliographic review of the literature from 1974 to 2007 J Exp Clin Cancer Res 2732 https://doi.org/10.1186/1756-9966-27-32 PMID: 18759983 PMCID: 2543010

14. Fanakidou I, Zyga S, and Alikari V, et al (2018) Mental health, loneliness, and illness perception outcomes in quality of life among young breast cancer patients after mastectomy: the role of breast reconstruction Qual Life Res 27 539-543 https://doi.org/10.1007/s11136$\underline{017-1735-x}$ 
15. Leinert E, Singer S, and Janni W, et al (2017) The impact of age on quality of life in breast cancer patients receiving adjuvant chemotherapy: a comparative analysis from the prospective multicenter randomized ADEBAR trial Clin Breast Cancer 17 100-106 https://doi.org/10.1016/j.clbc.2016.10.008

16. Gaton-Johansson F, Watkins CC, and Kanu IK, et al (2015) The effects of symptoms on quality of life during chemotherapy in africanamerican women with breast cancer J Natl Black Nurses Assoc 26 7-16

17. Tachi T, Teramachi H, and Tanaka K, et al (2015) The impact of outpatient chemotherapy-related adverse events on the quality of life of breast cancer patients PLoS One 10 e0124169 https://doi.org/10.1371/journal.pone.0124169 PMID: 25915539 PMCID: 4410996

18. Barbosa PA, Cesca RG, and Pacífico TED, et al (2017) Quality of life in women with breast cancer, after surgical intervention, in a city in the zona da mata region in Minas Gerais, Brazil Rev Bras Saúde Matern Infant 17 385-399 https://doi.org/10.1590/180693042017000200010

19. Perroud HA, Alasino CM, and Rico MJ, et al (2016) Quality of life in patients with metastatic breast cancer treated with metronomic chemotherapy Futur Oncol 12 1233-1242 https://doi.org/10.2217/fon-2016-0075

20. Ho SSM, So WKW, and Leung DYP, et al (2013) Anxiety, depression and quality of life in Chinese women with breast cancer during and after treatment: a comparative evaluation Eur J Oncol Nurs 17 877-882 https://doi.org/10.1016/j.ejon.2013.04.005 PMID: 23727448

21. Pierrisnard C, Baciuchka M, and Mancini J, et al (2018) Body image and psychological distress in women with breast cancer: a French online survey on patients' perceptions and expectations Breast Cancer https://doi.org/10.1007/s12282-017-0828-2

22. Tang L, Fritzsche K, and Leonhart R, et al (2017) Emotional distress and dysfunctional illness perception are associated with low mental and physical quality of life in Chinese breast cancer patients Health Qual Life Outcomes 15231 https://doi.org/10.1186/s12955-0170803-9 PMID: 29191208 PMCID: 5709963

23. Zhang $Y$, Fritzsche $K$, and Leonhart $R$, et al (2014) Dysfunctional illness perception and illness behaviour associated with high somatic symptom severity and low quality of life in general hospital outpatients in China J Psychosom Res https://doi.org/10.1016/j.jpsychores.2014.06.005 PMID: $\underline{25149028}$

24. Winters ZE, Haviland J, and Balta V, et al (2013) Integration of patient-reported outcome measures with key clinical outcomes after immediate latissimus dorsi breast reconstruction and adjuvant treatment Br J Surg 100 240-251 https://doi.org/10.1002/bjs.8959

25. Fayers P, Aaronson N, and Bjordal K, et al (2001) The EORTC QLQ-C30 Scoring Manual 3rd edn (Brussels: European Organisation for Research and Treatment of Cancer) [https://www.eortc.org/app/uploads/sites/2/2018/02/SCmanual.pdf]

26. Choi EK, Kim I-R, and Chang O, et al (2014) Impact of chemotherapy-induced alopecia distress on body image, psychosocial well-being, and depression in breast cancer patients Psychooncology 23 1103-1110 https://doi.org/10.1002/pon.3531 PMID: 24664939

27. Browall M, Ahlberg K, and Karlsson P, et al (2008) Health-related quality of life during adjuvant treatment for breast cancer among postmenopausal women Eur J Oncol Nurs 12 180-189 https://doi.org/10.1016/j.ejon.2008.01.005 PMID: 18343197

28. Kroenke CH, Kwan ML, and Neugut Al, et al (2013) Social networks, social support mechanisms, and quality of life after breast cancer diagnosis Breast Cancer Res Treat 139 515-527 https://doi.org/10.1007/s10549-013-2477-2 PMID: 23657404 PMCID: 3906043

29. Lindau ST, Abramsohn EM, and Baron SR, et al (2016) Physical examination of the female cancer patient with sexual concerns: what oncologists and patients should expect from consultation with a specialist CA Cancer J Clin 66 241-263 https://doi.org/10.3322/ caac.21337 PMID: 26784536 PMCID: 4860140

30. Hall E, Cameron D, and Waters R, et al (2014) Comparison of patient reported quality of life and impact of treatment side effects experienced with a taxane-containing regimen and standard anthracycline based chemotherapy for early breast cancer: 6year results from the UK TACT trial (CRUK/01/001) Eur J Cancer 50 2375-2389 https://doi.org/10.1016/j.ejca.2014.06.007 PMID: 25065293 PMCID: $\underline{4166460}$ 
31. Jolly TA, Williams GR, and Bushan S, et al (2016) Adjuvant treatment for older women with invasive breast cancer Women's Heal 12 129-145 quiz 145-146

32. Savard J, Ivers H, and Savard M-H, et al (2015) Cancer treatments and their side effects are associated with aggravation of insomnia: results of a longitudinal study Cancer 121 1703-1711 https://doi.org/10.1002/cncr.29244 PMID: 25677509

33. Laviano A, Koverech A, and Seelaender M (2017) Assessing pathophysiology of cancer anorexia Curr Opin Clin Nutr Metab Care 20 340-345 https://doi.org/10.1097/MC0.0000000000000394 PMID: 28598896

34. Velikova G, Booth L, and Smith AB, et al (2004) Measuring quality of life in routine oncology practice improves communication and patient well-being: a randomized controlled trial J Clin Oncol 22 714-724 https://doi.org/10.1200/JCO.2004.06.078 